\title{
Sexual Self-Concept through a Cross-Cultural Lens: Qualitative Case Studies of Iranian-American Women
}

\author{
Mitra Rashidian \\ University of New England \\ School of Health, Armidale, Australia \\ Emeritus Professor Victor Minichiello, Ph.D. \\ Australian Research Centre in Sex \\ Health \& Society, La Trobe University, Melbourne, Australia \\ Rafat Hussain, Ph.D. \\ Australian National University \\ ANU Medical School \& Research School of Population Health \\ Canberra, Australia
}

\begin{abstract}
Recently scholars have examined more closely the topic of female sexual self-concept as an aspect of sexual well-being. Few studies have focused on migrated women's life experiences cross-culturally, and how that informs a woman's view of herself as a sexual being. This is particularly true about most middle-eastern cultures, including Iranian-American women. Four case studies draw on qualitative data from interviews with first generation Iranian-American women in the USA to describe the sexual selfconcepts evolving as a result of life in both cultures. Applying narrative methodology and feminist theoretical perspectives two themes were revealed. These are i) the influence of family power, and ii) patriarchal social practices. The analysis introduces a multidimensional aspect and process associated with each woman's view of her sexual self-concept, which takes into account their behaviours, cognitions, and emotions developed in each life stage, and inform her sexual subjectivity (view of herself as a sexual being). Implications of these findings for clinicians and policy makers involved in sexual health care for women are briefly discussed.
\end{abstract}

Keywords: sexual self-concept, cross-cultural, Iranian-American women, sexuality, power relations

\section{INTRODUCTION}

Sexuality, as a core part of a human life experience [1], has been historically studied by scholars. Traditionally, this involved sexual dysfunction, reproductive care, and STIs [2-3], but a much wider and more inclusive framework includes emotional and mental sexual-well-being as a significant aspect of sexual health [4], and sexual self-hood (i.e., view of self as a sexualbeing) [2]. Qualitative investigations [5] have been a powerful tool in exploring women's sexual self-hood. For example, Daniluk [6] used both a feminist and qualitative approach to explore the experience and the meaning-making process of female sexuality, and to learn about women's sexual experience and the associated meanings with those experiences. Ellison [7], also revealed the importance of a woman's sexual-self by stating that "our sexual-self is that aspect of who we are through which we experience and express our sexuality" (p. 13).

Sexual self-concept has regularly been studied in western society, within the mainstream female population, which includes sexually abused homeless youth [8] and people with 
physical disabilities [9]. Sexual self-concept includes various complexities, in particular amongst women from non-western populations [10]. But research on female sexual selfconcept for non-western immigrant women particularly Asian \& Middle Eastern women seems to be limited. Much more information is needed on the dichotomy between pre-migration cultural norms and values compared to post-migration. It is likely that the differences between these two value systems may potentially impact on the women's view of their sexual self-hood, and possibly influence and change ideas about what are sexually permissible, which can also impact their sexual health [11].

In the following sections, we reviewed the literature about certain cultural challenges that Iranian-American women experienced both pre and post migration. This is followed by an examination of developmental aspects of female sexual self-concept.

\section{BACKGROUND INFORMATION}

The 1979 political revolution in Iran had a profound impact on many aspects of public policy and social discourse. Many of the resulting issues relate to a shift from a pro-western society to one that underscores the traditional Iranian collective culture, which emphasized curtailment of women's social individualism [12-13]. The on-going political issues led many urbanized and educated families to immigrate to what were believed to be more liberal nations, including the United States and Canada [14-15]. A significant number of the Iranian women migrated to the USA due to spouse's political situations post-revolution.

Historically in Iran, discussions related to women's sexuality were taboo [16]. Politically, these issues were even more suppressed after the revolution. At that point, migration was seen as a way of escape from cultural impositions and social stigmatizations designed for women. Examples of the impositions that women can experience in Iran include: i) sexual socialization [17], ii) social construction of sexual life after divorce [18], and iii) a lack of female sexual rights [19]. In addition, the help-seeking behaviours of Iranian women related to sexual disorders are of concern because they partly relate to the experience of shame and these women's belief of the inability of doctors to provide adequate help [19]. A primary question for Iranian-American women arises: how does she question and re-examine female gender roles and personal relationships across migration? In addition, how does she make sense of how her life experiences, both pre and post migration, shape her current sexual self-concept?

The current population of the Iranian-American female in the United States is estimated to be about one-half million. It is suggested that the Iranian-American assimilation process of individuals is similar to that of other immigrant communities in the United States. Each Iranian individual has experienced their own unique assimilation process according to their daily interactions with others, their unique experiences, specific economic status, and cultural ties [20].

\section{SEXUAL SELF-CONCEPT}

Sexual self-concept develops through subjective interpretations of sexual experiences [21-22], sexual socialization [23], social contrasts [24] and from mutual relationships over time [25]. Sexual self-concept has been known as a view of self as a sexual person, which involves sensations that are produced [26]. As Johnson and colleague [8] note: "The belief in one's ability to deal with oneself and others as a sexual person and to feel in control of the sexual aspects of one's life" (p. 45). Others have suggested that "sexual self-concept is a multidimensional construct that refers to an individual's positive and negative perceptions and feelings about him/herself as a sexual being" [27](p.277). Winter [28] suggested that the 
concept of the self as a sexual person is not solid or fixed, and develops with age and time. The literature on self-concept reveals that it also includes sexual self-efficacy (i.e., the level of confidence in one's ability to engage and/or refuse sexual behaviors) [27]. Sexual self-concept is conceptualized to be the difference between desired and actual sexual activities, including its negative feelings such as guilt, shame, anxiety, and feeling pressured or forced, that are associated with sexual activities [29].

Feminine ideology has focused on the ideas, norms, and restrictions about what constitutes normal, acceptable, ideal womanhood, including sexual expression [30]. Other variables that may impact sexual self-concept are introduced as sexual agency [26], sexual subjectivity [31], sexual self-esteem [32], and sexual empowerment [33]. Finally, the examination of sexual selfconcept models provides a broader sexual context via its relationship with other aspects of sexuality, such as sexual cognition, affect, interpersonal, behavioral, and socialization. Various scales have been developed such as the Multidimensional Sexual Self-Concept Questionnaire [34](MSSQ), and the Women's Sexual Self-Concept Scale [29](WSSCS) that are now widely used in quantitative studies.

Qualitative studies also reveal important insights into the development of female sexuality continues to be influenced by cultural double standards such as the importance of sex for males, and the lack of encouragement for female sexual desire and empowerment [35]. The development of female sexual subjectivity not only needs the experience of sexual pleasure, but the experience of emotional and cognitive interaction and reflection in order for females to have sexual self-awareness. This is essential if they are to ever know their sexual-selves [22]. A female who knows her sexual-self eliminates self-silencing in intimate relationships, and increases self-esteem and the sense of empowerment in both sexual and non-sexual arenas [21]. Sexual agency refers to women having a voice in their intimate relationships, and gives them the power to resist sexual double standards. A lack of sexual subjectivity lowers a woman's ability to effectively communicate her wants and desires in her relationships, and therefore negatively impacts her both physically and emotionally [36].

Of significance to our study is the work of Schnarch [37] who proposed that a woman may develop, across her lifespan, a reflected sexual-self through the composite social practices within a male dominated culture. Sociocultural and situational factors impact women's sexual expression in varying degrees [38]. Therefore, women's sexual self-concept is likely to change over time based on life experiences [39]. Other scholars [40] argue that the influence of cultural ideologies experienced by women during their upbringing may create difficulty in their ability to identify their own sexual-self. This sense of self is primarily a social entity that is culturally constructed as the human self is a "reflected sense of self", dependent on culture and group identity [37]. One effect of a reflected sense of self, for example, is that women may choose to engage in sexual activities that are desired by their partners even when they disagree with them, which will impact her self-view as a sexual being [22].

Given the limitations of the literature on the sexual self-experiences of women born in Middle Eastern cultures and who have subsequently moved to the West, this article aims to explore the Iranian-American women's sexual self-concepts. With the focus on the effect of socialization, migration and unique life events, our case studies offered first-hand information about how each woman is able to describe herself as a sexual being by reflecting on her individual past, and current sexual experiences, cross-culturally. 


\section{METHODOLOGY}

We selected four stories as case studies for this article from our larger qualitative research (2006 - 2011) [41]. The original sample included twenty four first generation IranianAmerican women, age 18 years and older, and residents of Southern California. Within the context of our study, first-generation Iranian-Americans refer to those individuals who immigrated to the United States from Iran [20]. The recruitment process began once the University's ethical approval was granted. The study information and the types of questions were provided initially by family physicians, followed by a snowball sampling technique for the recruiting process. After obtaining signed consents, an informal semi-structured conversational style interview technique was used [42]. Pseudo names protected the identity of the participants. The four informants were selected because they offered an in-depth understanding of the sexual life experiences within Iranian culture and articulated the themes traversing all other interviews. Table 1 below provides a description of the four women.

The first author, a first generation Iranian-American female herself, and a psychotherapist, conducted each interview in order to facilitate a safe environment for the participants to share their stories. Participants used mix language of both English and Farsi, depending upon their comfort level and understanding of differing concepts. Many sexually related concepts were verbalized in English, as participants were mostly unable to find comparable words in Farsi (official Iranian language), and/or felt more expressive using English language. Participants' demographic information, both pre and post migration are presented in Table 1 and Table 2.

Table1: Participants' Demographic Information at the Onset of Migration to the USA

\begin{tabular}{ccccc}
\hline $\begin{array}{c}\text { Participant's } \\
\text { Name }\end{array}$ & Mahnaz & Mitra & Ziba & Aida \\
\hline $\begin{array}{c}\text { Year of Migration } \\
\text { to USA }\end{array}$ & 1977 & 1985 & 1993 & 1980 \\
Age & 17 & 21 & 11 & Married \\
Marital Status & Married & Married & Single & Jewish mother \& \\
Religion & Muslim & Muslim & Muslim & Incomplete High \\
$\begin{array}{c}\text { Educational } \\
\text { Background }\end{array}$ & Incomplete High & School & School \\
$\begin{array}{c}\text { Self-Perceived } \\
\text { Socio-Economical } \\
\text { Status in Iran }\end{array}$ & Higher Status & Middle Class & Middle Class & Higher Status \\
$\begin{array}{c}\text { Reason for } \\
\text { Migration }\end{array}$ & Marital Decision & Spouse Decision & Parents' Decision & Legal Issues \\
Prime Source of \\
Income
\end{tabular}

Each unstructured face-to-face interview lasted approximately three hours. Interviews were tape recorded in an attempt to extract more details and elaborate on certain areas of importance. Interviews began with a broad question: "Looking back at your life, living in both cultures of Iran and the USA, how do you see yourself as a sexual being today?" Subsequently, probing questions were used in order to explore areas of interest (i.e., "Please tell me more..."). 
Interviews explored a broad range of concepts including; i) - How did they learn about their sexuality growing up in Iran, ii) - How past experiences reflected on their current intimate relationships iii) - How each woman was able to view herself as a sexual being as a result of living in both cultures, iv) - What were the contributing factors that formed their current sexual self-concepts.

The first author transcribed each interview for confidentiality purposes. Each case transcription was read through several times in order to gain an in-depth understanding of each story. Additionally, the first author sought consultation from advisors in order to be aware of any biases. Conceptual notes were made on the transcripts. Attention was paid to how events were related, how each story linked past and present life experiences. Quotes were selected based on key themes emerging in the data, issue of collective concerns, participant's emphasis, and the role it played in the story voiced.

Table 2: Participants' Demographic Information at the Onset of Interview in California,

\begin{tabular}{|c|c|c|c|c|}
\hline $\begin{array}{c}\text { Participant's } \\
\text { Name }\end{array}$ & Mahnaz & Mitra & Ziba & Aida \\
\hline Age & 47 & 43 & 26 & 46 \\
\hline $\begin{array}{c}\text { Years Lived in } \\
\text { USA }\end{array}$ & 30 & 22 & 15 & 27 \\
\hline Marital Status & Divorced & Divorced & Single & Divorced \\
\hline Level of Education & Masters of Science & $\begin{array}{l}\text { Incomplete High } \\
\text { School }\end{array}$ & Graduate Student & High School \\
\hline $\begin{array}{c}\text { Employment } \\
\text { Status }\end{array}$ & College Professor & Cosmetologist & School Counsellor & Self-Employed \\
\hline $\begin{array}{c}\text { Self-Perceived } \\
\text { Economical Status } \\
\text { in USA }\end{array}$ & Middle Class & Middle Class & Middle Class & Upper Middle Class \\
\hline Source of Income & Employed & Self-Employed & Employed & Self-Employed \\
\hline
\end{tabular}

\section{RESULTS: THE CASE STUDIES}

Each participant voiced her story of how her sexual self-concept was constructed. Two main categories of themes emerged from narratives. The first category included family power and life events during childhood, which was central to internalizing her submissive female role. For participants in each case study, early sexual experiences were viewed negatively, as they were characterized by "secrecy, isolation, fear, shame, guilt, and ignorance." The second category is linked to Iran's official dogma (i.e. religious doctrine, education, mass media) that often defined and limited her proscribed sexual-self, and the challenges to these notions as a result of the migration to the USA. The differences between the two cultural experiences, while initially giving them a more optimistic self-view, also were combined with older feelings of shame and guilt, which led to conflictual and confusing thoughts about differentiating from their home culture.

\section{MAHNAZ'S STORY}

After Mahnaz expressed her interest to participate, we met at her apartment. She introduced her story as "scary". During the interview, sexually related words were verbalized in English 
and others in Farsi. Mahnaz began her story by revealing a "significant life changing experience". At the age of five she was sexually molested by a male housekeeper.

“...after breaking my brother's toy, I feared punishment by my mother, who was not home at the time. The housekeeper kindly promised that he would fix the toy...for my comfort he took me onto his lap and eventually attempted to penetrate me. My mother arrived and was horrified at what she thought she saw. She began hitting me while questioning about what was going on...I did not know what to do... (looking sad...)."

Mahnaz's family held her responsible for the "crime of participating in a sexual act" and for "not maintaining family honour." However, she felt a strange sensation "there" without knowing what it was and in which it remained a part of her life onto adulthood.

"I re-experience those same feelings by touching myself, which soon became a habit I kept as a secret across my life. The confusion about the incident, the body sensation, and fear of further punishment kept me isolated...my younger brothers became my chaperon anyway..."

Mahnaz grew up with fear and confusion throughout the reminder of her childhood. At the age 9, she was molested for the second time by her family physician.

“... as the doctor was examining my throat, he moved his hands to my chest and began to kiss me. I was fearful of him... and... confused for sensations I felt..."

Due to fear of punishment, she kept the incident to herself. Both molestation episodes and the confusing feelings within her body made her feel "bad" about herself. She felt ashamed and more confused when she used her hand to linger on her genital long enough, to experience the pleasurable sensation. Often, she made a silent promise with herself that she would touch herself just one more time and never again, but she could never keep her promise. Feeling fearful that God was watching her, still, often she did give in, masturbated as surreptitiously and quickly as possible in attempt to avoid the feelings of fear, shame and guilt. Meanwhile, she carefully attempted to hide her bodily changes and curiosity as secret.

“...I was thirteen years old when I made my first suicide attempt by taking pills...my father punished me by mistaking my menstrual period as a sign of losing my virginity... I did not know what was happening to me and why I was bleeding that way and from there... (Tearful)."

Mahnaz felt "sad" when she woke up in the hospital and didn't die. She was released from the hospital to a married male family friend. On her way home she was crying, and upon the kind offer of the family friend, she told him about her parents' abusive behaviour. For the first time Mahnaz felt supported. But, sadly, as he held Mahnaz in his arms for comfort, he began to fondle her breasts. Confused and fearful, Mahnaz ran away and walked all the way home. However, he continuously approached Mahnaz as various opportunities arose and continued sexually "molesting" her despite her "protests".

"...I eventually enjoyed being with him that way...and...learned that was sort of having sex... a sinful thing... but, no matter what I said, I ended up surrendering myself to him....another secret...(Covered her face)." 
Finally, the secret was revealed. Once again, Mahnaz was blamed for "seducing" a grown man with a wife and two children. This time she was beaten extensively with a belt by her father and she made another suicide attempt by overdosing on pills and woke up in the hospital hearing her mother ordering the nurses to "let Mahnaz die", as she was the shame of the family. Mahnaz was send to Tehran to live with her "controlling" grandmother. However, eventually the controls were "ineffectual", which gave Mahnaz the opportunity to explore other activities outside school felt comfortable making friends at school, but, still was not allowed to associate with them alone.

At the age of 16, a husband was chosen for her who was twenty years her senior, a widower with two children who needed a step-mother to look after his children. To avoid marriage, Mahnaz made another suicide attempt. Rather than marry her, her fiancé, now her primary decision maker, decided to send her away to the United States so that she could be away from both families. Mahnaz explains:

\section{“...I started my new life in Los Angeles at the age of $17 . .$. f finally got my break!...”}

Mahnaz lived with her fiancés family, he returned back to Iran and announced to both families that the engagement was over and that Mahnaz was not to return back to Iran. "...it sounded like a miracle" she said. After completing high school, Mahnaz got a job, and attended College. Her ex-fiancé continued to help her financially occasionally. Knowing that she would not be welcome back to Iran, Mahnaz never wanted to contact her parents; however, she missed her siblings.

"... Finally, me, the lifelong shame of the family was sent as far away as possible from them... but, this was the beginning of freedom for me..."

She enjoyed attending college and learning about opportunities. After college, she became a teacher. Financial independency made her feel "powerful". While working, she started sociology program, and it was then that she met her husband. Mahnaz said:

“...feeling uncomfortable to share about her pre-marital relationship... (Blushing). He was a very nice man. After one year of a steady relationship, he proposed, and I accepted. We did not have a traditional Iranian wedding... and I even never received a wedding present from my parents... (Silence)..."

While raising their children, Mahnaz decided to return to school for higher education and eventually became a college instructor. Across marriage she found that having sex with her husband felt "sinful" and "shameful", but she "went along with it" since she believed it was her "duty" to "satisfy" her husband's sexual needs:

"I felt fearful to share my sexual feelings. They may have been considered bad by him. There were times when I was next to my husband in bed, holding him from back, skintight, while I felt thousands of miles away and apart from him. Ohhhh....eventually he had an affair and we got divorced."

After divorce, Mahnaz kept herself away from her Iranian-American community. She felt "unwelcomed" by them as a "divorcee" woman. Since her divorce she has not had any another intimate relationship, whether with Iranian or non-Iranian men. She had minimal contact with 
her family in Iran. This was "working better" for her. She believes that she was severely emotionally injured first by her parents, rules and life in Iran. Her injured emotions, guide her life to a large extent:

"I see...(crying)...how I was destroyed as a result of my past...following a patriarchal system so blindly...if that is the right pathway...how can the system destroy lives... sometimes I even think that perhaps my mother had no choice since she learned from that system how a woman should behave to be a good woman...well, who knows why...I learned to live a life that sacrificing its women did not matter to anyone, for the sake of culture ...even including my own parent...this is normal in my culture ...(Silence...)."

Although Mahnaz felt she felt freer in the United States, she never felt fully free of the cultural "shackles" that had placed a hold over her mind since she was a young child:

"I still do not have a peaceful life... my sexual-self...it is who I am today...sexually, I know how to please myself... still masturbating... beside spending time with my children , I don't want anything else to look for..."

Her story supports her last words during this interview.

“...despite my successful professional life, I feel trapped by my past... (Looking down).”

\section{MITRA'S STORY}

We met at her beauty shop after working hours. Mitra, a 43-year-old "cosmetologist" presented as a regal, elegant woman who interprets her sexual life experiences as filled with "betrayal and pain".

"My family was powerful and conservative Islamic... therefore, men dictated women's behavior and we had to obey..."

At 14, Mitra was "stunned" by the news of her "imminent" arranged marriage. She was under the legal age, but her father's influence authorized her marriage. Mitra thought of marriage as a "party" and was completely unprepared for what came next.

“...I did not know anything about marriage...nothing...nothing about what was happening when one becomes a bride except looking pretty..."

After the reception, instead of "going home with parents", she was "forced" into a room, with a man as her husband. Women remained outside the door while giggling, and making jokes about her going inside the room. Her husband had to have sex with her and prove her virginity by showing both families a blood-stained white cloth as part of their tradition. She described her first sexual experience as one of "shocking".

"...Up to that night, I did not even think about men...he told me to open up my legs as wide as possible for him to penetrate me...had no idea what was happening... why was he allowed to touch my vagina when I even never touched myself ... what was done there for him...touching it was a bad, sinful thing to do for a girl...I remember feeling afraid...ever since, up until I moved from Iran, I kept my feelings to myself...no one cared and I just had to obey my husband...after moving here, eventually I learned that 
what happened to me was nothing short of being raped as a child...in the name of marriage..."

Her first period was still six months in the future after getting married. In the next nine years, Mitra gave birth to two children and kept her "submissiveness". Even though her husband had extra-marital affairs she remained loyal and satisfied her husband's sexual demands. After migration the United States they moved in with extended family in California, where life among her relatives proved to be a microcosm of her Muslim upper-class life in a small town in Iran. Overtime, Mitra felt challenged by social differences between Iran and California and the "difficulty" placed upon her.

“... I wanted to know more about this new place...to learn the English...to drive a car. But, my husband did not give me permission...Instead, he reminded me about my prime household responsibilities...my parents told me the same thing...as a woman my place was at home to take care of him and our children... as a woman I was considered incapable of learning professional skills...I even didn't have a High School diploma..."

However, she witnessed non-Iranian women's life style in Los Angeles and wanted to be like them. Within a few years, despite her family disagreement, she asked for divorce due to her husband frequent affairs with other women. To her surprise, her husband agreed, because he wanted to "play around freely". After her divorce, Mitra, while still a traditional women, decided on cosmetology given her lack of English fluency and higher education. Her exhusband supported her financially for cosmetology school, including paying her mortgage, after their divorce. Mitra said:

“...Though not unusual in Iranian culture, this arrangement is a modern-day extension of a very old tradition, jayrat (zeal), which holds that a woman always belongs to her husband, from virginity to death...otherwise he would have risked his honor due to possibility of me getting married again which means having sex with another man."

Although she had a boyfriend, she refused making permanent commitment. Years of betrayal and cultural traditions had fostered fear and mistrust.

"I don't know anything about my...self...didn't know that my...self...is different from what I am told that I am...know nothing about my sexual-self...I even didn't know what it was or how it was related to me until this interview...(smiling)...Perhaps, it will take a while for me to discover it. When I do, I will share about it...”

Mitra felt both the strong hold of her submissive identity while experiencing some level of comfort with her new life in the United States. Stepping outside home cultural boundaries is far more difficult than she anticipated.

\section{ZIBA'S STORY}

Ziba, was born in Iran and moved to India at age five. Her family migrated to USA when she was eleven years old. She described her home as a "deeply religious household," a place for "prayer" and therefore to be kept "as clean as a Mosque." That included "preventing nonMuslim people from visiting their home, which could make it "unworthy of Allah". We met at her home upon her mother's approval. Life in India included wearing conservative outfits because she was a girl, had limited all female friends and activities, and saying daily prayers. 
“...being a female...expressing about yourself as a sexual being...sex talk... are taboo topics in our culture... in fact... really BAD...sinful subject to bring up ...being a good girl is all about how my actions, thoughts can keep my family honor...within Persian (Iranian) community...to me...it all meant not to share the truth about how I was feeling, thinking... as I actually am..."

As she became older, her limitations increased but not for her older brother. She was never allowed to ask questions about puberty and associated experiences such as her bodily changes, and the feelings that were generated.

“...I learned about a woman's reproductive cycle from a video that I watched in fifth grade as part of school activity here..."

The saddest message for her was that "as a girl, she was less valued than a son". Primarily she questioned the "fairness" of girls' treatment even when and after she moved to the USA.

"Once we arrived to L.A., additional new rules were applied to both me and my brother. ...we were...forbidden to speak English in our home...forbidden to have American friends. However, my brother was allowed to have a non-Iranian girlfriend when he was $15 . .$. because he was a boy."

Ziba continued to experience "confusion" and "frustration" about having to measure up to the "unreachable, impossible, made up standards" standards of a "perfect Muslim girl". Her focus was primarily on school activities and on "fitting in" with other girls at school. At home, her parents continued to "remind" Ziba about "good Muslim girl" duties.

“...My mother worried that I was becoming Americanized...she was correct...since very soon I wanted to be like my friends...it was fun...they talked about boys... sex... how it felt to them...eventually, to fit in, , I changed my hijab as soon as I got to school and changed again when it was time to go back home...I became an American girl at school and a perfect Muslim Iranian girl at home...it was very frustrating to do this in particular when my brother had no restriction...he had girlfriends...(silence)...(tearful)...(voice shacking)...this was A LOT FOR ME TO HANDLE...IT...WAS...NOT...FAIR (shouting...crying)...I still hate myself for being a girl..."

Soon, Ziba had a secret relationship with a college student from India.

“...at sixteen...he raped me... (Tearful)... was my first sexual experience ...losing my virginity... that way... made me feel as if I was a doomed person...had to be kept as a secret... for family honor..."

Receiving a promise of marriage, she felt "forced" to satisfy his sexual needs as often as he demanded sex for the next two years. However, Ziba "dreamed" about going to college and forming a "different life".

“...eventually I was able to focus on my academic and professional goals..." 
She convinced her family about enrolling in a four-year college in another city, rather than getting married to someone that would have been selected for her by her mother.

"...I was desirable even though I was not a virgin. I dated other boyfriends and had serious relationships with three...each boyfriend was kind, but..., none of them were Iranian or Indian...never took that chance since I was not a virgin. (Crying)."

Her last boyfriend was an American. But, she had not yet told her mother about the relationship since he was not Muslim.

"Sometimes I think that my first boyfriend took a whole lot more away from me than my virginity..."

As a young woman she felt confused about her "different way of thinking" as it felt offending the traditions and values she had grown up with. She lived a separate secret life apart from her family, where she can be expressive about herself. She feels lucky for moving to the USA at the age she did, since this allowed her to learn about her passions, desires, and ultimately herself.

“...as a perfect Muslim girl, I do read Quran, and pretend to pray five times a day... but, the real me ...I... am very sexual... makes me feel free as a person...because I teach at school I meet girls who were raised just like me...I have been helping a few of them with questions about themselves...the truth is that there are no real answers... to survive this battle, our young generation follow traditions when around family and friends...other times, we are just ourselves...(looking sad)..."

Ziba's biggest challenge was to find a conscious balance in order to maintain both perspectives that she was raised with in Iran, India, and in Los Angeles.

\section{AIDA'S STORY}

Aida was born in Germany to a Muslim Iranian father and a German-Jewish mother. We met at her house. Once the prime question was asked, while laughing, she said:

“... isn't it true that our culture says... that talk about sex, orgasm...all that is sinful for women... sex...sharing bodies...love...touching...feeling sexual...or...anything sexual for women is ...sinful ... when I talk about sex... my friends tell me I am a whore...(laughing harder)... since when talking about sex is permitted....?"

Aida lived a "comfortable, secular lifestyle" in Germany until she was 5, when her parents divorced. A year later, her father "kidnapped" her and took her back to a small city in Iran in an attempt to force her mother to join them to form a "traditional Iranian family". Aida's mother refused mainly because her husband could have prevented her from leaving Iran per law. Aida was seven years old, her mother committed suicide.

“...I still recall my happy childhood days in Germany...but...in Iran... I was to change in order to become a traditional Iranian girl... I should have been left behind in Germany to grow up as a free German girl..." 
Because of Aida's blond hair, fair-complexion, and hazel eyes, the local community in Iran was curious about her. Aida's father re-married twice, and each time she felt mistreated by her step mothers.

“...teen years were tough for me. Boys noticed my beautiful face and body, and wanted to talk to me... gossip began to circulate, and my father kept me under constant observation. I was being punished because I was a girl and a beautiful one too."

At fifteen, her father "forced" Aida to marry a man 20 years her senior. Aida was subjected to a "virginity verification test" by a doctor before her marriage. She felt "humiliated" and was "traumatized" by the experience. During the first few years of marriage, Aida became a housewife and was given limited options by her husband. Sex was not a "pleasure" but a "painful chore", causing ongoing trauma. Aida's husband had an "insatiable sex drive".

“...Every night he demanded sex multiple times, telling me it was my duty to provide it, regardless of whether I wanted it or not. Each time I was, in effect, raped...therefore...I believed that being a woman was a humiliation in and of itself. Night after night for many years, his routine remained unvaried... He would spit...into my vagina to lubricate it... and then mount me in the missionary position...usually at 20-minute intervals four to six times per night...I was never relaxed nor was I emotionally or physically excited or aroused and never willingly engaged in sexual activities with my husband....sex with him always hurt...and I would always describe it as rape. It was all humiliating when he spit on my vagina...It felt as if he was spitting on my soul."

Five years after her marriage and birth of two children, Aida found herself attracted to another man. He was "patient and encouraging", shared a pleasurable side of sex.

“... (Tearful)...I even didn't know how to describe my feelings...with him... (Looking down)...I felt so warm...I became myself when I was talking with him on the phone.... the real me... that I lost years ago... that was never valued or acknowledged or loved....there is nothing but nothingness for women of Iran..."

Sometime into their relationship they made love. "It felt good," she said. "It felt right to do." However, her happiness did not last long and her infidelity was uncovered.

“... (Crying)...As we met for the last time, we were caught and taken to jail. The police hurled insults at me, calling me a whore... while brutally beating him...next...my father and husband arrived, both with enough influence to get me released into their custody for the night. However, I was immediately sentenced to be executed by stoning within a short few days...aaahhhh... That night, I had to say goodbye to my life in Iran...to my kids...I kissed them goodnight...opened a window and stepped outside taking with me only my wallet... (Tearful)...don't know how...but... managed to get myself to the IranTurkey border and went to Istanbul..., and with the help of a friend, eventually...I made it to the United States... (Long silence...)."

To feel "safe", and due to "English language barrier" Aida maintained close contact with the Iranian community, and worked at various Iranian restaurants, getting paid "under the table" for less than minimum wage. She did not mind doing the work in exchange for her "freedom". She quickly started to learn English. Having limited money, she read old newspaper to help her to learn English. Soon, she saw an advertisement for a job in a boutique. She borrowed an outfit 
from another waitress and applied for the job in person. Her German-Iranian feature, coupled with her ability to communicate with wealthy Farsi-speaking patrons, helped her get the job in Beverly Hills. For the next few years Aida developed her skills in fashion, and devoted her time to learning all the aspects of this business, while avoiding all intimate relationships. Also she managed to visit her children two other times in Turkey without her husband's permission. She eventually asked for a divorce, and it was granted to her, along with revocation of her sentence to be stoned. He agreed to not press charges against Aida.

"...the only thing that kept me going was the hope to make enough money so that I could bring my children to USA. I just had to do it... every night I kept praying to God to give me strength so that I could survive my life and have them by my side...every night I prayed for the well-being of the man that I fell in love with, and asked God for forgiveness...every night I cried myself to sleep... (Crying)..."

Aida eventually established her own boutique. It became very popular among fashion leaders locally and in particular among the Iranian community. During this time she also received her Green Card and started to travel overseas to further expand her fashion business. To Aida's relief and happiness, her husband finally decided to send the children to live with Aida with the promise of financial support. She ultimately had her children with her, but the financial support never came:

“...I was constantly... working, struggling, and trying to make a good living for them... I went through several different businesses...made financial mistakes... went through bankruptcy... but no matter how difficult it was, I gave my kids the best that I could..."

As a beautiful woman, men showed interest in her, and she found herself responding back to them. She still felt a "cultural tie" to the Iranian community, but, as a single woman, she did not feel "right, safe" initiating an intimate relationship:

"...I worried about my image in both the Iranian community in Los Angeles and in Iran among my family members. I kept my sex life a secret, trying to maintain the image of a chaste woman... I also felt guilty for having sexual feelings. But, I was able to convince myself that in Los Angeles it was acceptable for women to have intimate relationships as long as it was hidden from the Iranian community. Eventually, I started thinking and feeling differently about myself as a sexual woman... dong this was not an easy one... many times I...felt guilty, shameful, and sinful, for having sex with other men."

As her business grew, she began to feel more empowered and less connected with her Iranian culture. Through this change, Aida gained a sense of "self-worth". As a successful businesswomen she felt comfortable and "in control" of whom she wanted to have intimate relationships with.

"I am a complete women now...I know all about my sexual desires...every time I have sex with a different man, I make a new discovery about my body and desires...I have learned that masturbation is a healthy way of living, and I don't deny it to myself...I am a highly sexual woman and proud of it..." 
With every new relationship, Aida felt more "empowered" and more "in touch" with her "sexual-self". She was surprised by the level of "sexual enjoyment" she experienced in subsequent relationships with both Iranian and non-Iranian men:

“...This was the time for me to enjoy myself and my womanhood. It was not easy at first to allow myself to experience sexual feelings, but eventually I learned to trust my boyfriend...during all the years I have known him, he is the only one who has proven himself to truly love me... not my body... my father who used to come to L.A. a lot met with him too and he liked him..."

Aida still feels influenced by her past. Her successful business offers her a sense of "power" and "independence" that she never experienced before. Still, she feels vulnerable in sexual relationships and controls her "emotions" by keeping them largely to herself.

"If I managed to run away from death, then, I can do just about anything."

\section{DISCUSSION}

This article explored the sexual self-concepts of first generation of Iranian-American women using four case studies. Our aim was to learn how various life events experienced in Iran and the United States shaped their view of themselves as sexual beings. Each case provides diverse insights into the nature of Iranian-American women's sexual self-concepts. The rich narratives reflect the realities of Iranian-American women's sexual life from their own perspective, shaped both in Iran and USA, and establish a cross-culturally based understanding of sexual self-concepts. There is a universal message that has been taught to women who were subjected to a culture that supports patriarchy. It is that gender inequality is an inherent aspect of politics, religion, and culture, with real consequences for women [43]. It creates within the women tremendous pressure, which includes the suppression of their true sexual-selves, and creates a mandated compliance with female submissiveness [35].

Each case study illuminated the many internal conflicts and social challenges experienced as a result of cultural clashes. At the time of interview, these conflicts were still affecting their lives. Although difficult, it appears that each participant had learned how to self-reflect, as opposed to being controlled by other people's perspectives. This new skill of self-reflection enabled them to change certain beliefs and behaviors, and also helped motivate them to trust themselves in a way they could never have done prior to migration. These narratives clearly show the many ways in which these women were socialized in adolescence and adulthood, and how this unfolds to influence their understanding of their sexual self at the time of the interview. Each story reflects on social identity theory, which suggests that personal definitions are associated with gender, culture, religious affiliation, and socio-economic status [44].

There are both systematic individual differences and similarities among their stories. While living in Iran, their view of womanhood shared similarities such as agreement with submissiveness, and conforming to cultural norms. Post-migration, they collectively realized that their beliefs had been shaped by Iran's patriarchal culture. Other similarities that presented challenges included psychosocial pressures, conflicting sets of cultural expectations, and the pressure of role duality. This is in line with other research that suggests that many women after migration feel obligated to maintain multiple roles from both cultures as survival mechanisms [45]. Within this context, variation in autonomy is partially due to the fear of rejection from their family of origin, as well as breaking conventional Iranian sexually 
proscribed norms for female adults. However, each story supports that upon arrival to the United States, women who received less help from immediate family and friends, took greater charge of their lives more quickly, and developed a higher overall level of autonomy. This study sheds light on an important aspect of the migration of the Iranian-American women and those with similar cultural background. It does this by portraying women's alteration of their sexual-self concepts across migration. This gradual alteration takes shape as women adapt to the host cultural norms, while retaining their home cultural ties and messages about themselves as sexual-beings. Ellison's theory [7] supports the finding that it appears likely that these women's pre-migration view of their sexual-self serves as a fundamental foundation to their sexual self-concept shaped post-migration. Our findings suggest the need for more qualitative studies to understand female sexual self-concept for other immigrant women from non-western patriarchal societies. Additionally, our narratives suggest that there are systematic individual differences in female sexual self-concept. These differences highlight the multilayered nature of women's sexual self-concepts and offer insightful understanding of the cognitive mechanisms involved in female sexuality. Plus, in qualitative studies, there is a need to add cross-cultural perspectives to the existing sexual self-concept with the focus on marginalized women.

\section{IMPLICATIONS}

Our findings suggest several important social and clinical implications. Each case study showed that knowing about the sexual self-concept of immigrant women may work as a valuable tool in understanding gender specific social norms within diverse cultures. In addition, understanding women's perception and affective views could provide information regarding the formation of their self-worth and self-esteem. This suggests that sexual self-concept, if developed in suppressive environments, negatively affect women's' sense of autonomy and empowerment within society. This article provides a starting point for clinicians to target specific areas in their effort to modify a woman's negative sexual view of self across migration.

Due to the cultural differences between the US and Iran, it took years for these women to understand and appreciate their newly discovered sexual-selves, and to realize their new sexual freedoms. But, they still, to various degrees, hold earlier beliefs about their sexual-selves and sexual behaviours. In each case study, none of the participants made a direct reference to experiencing any form of sexual disorders. However, they shared about having difficulty participating in sexual activities. While this is not per se an indication of having a sexual disorder, it can still be an area of concern. Other researchers suggest that women in Iran have difficulty sharing sexual concerns with their physicians [46]. Therefore, as a part of effective sexual health care, it is essential for health care professionals to utilize a cross-cultural approach when dealing with this population. The core aspect of cross-cultural competency is the health care professionals' skill in empathizing and facilitating open communication with their culturally diverse patients. It is especially important for health care professionals to understand how powerful the cultural taboo against discussing female sexuality effects women both pre and post migration. Therefore, more training about a cross-cultural approach related to sexuality with female immigrant population is proposed.

This article does not purport to represent all Iranian or Iranian-American women. But, it makes an important contribution in understanding the factors affecting female sexual selfconcept of women cross-culturally. Future studies that investigate larger samples of such narratives can help to substantiate these findings, and offer further insight into the IranianAmerican female sexual-self. In conclusion, sexuality in the Iranian-American community is a 
concern due to patriarchal values and established gender roles, which all too often eliminate the opportunity for women to express themselves as sexual-beings.

\section{CONCLUSIONS}

As we explored the sexual self-concepts of the Iranian-American women, we learn that there is a marked difference between cultural norm expectations and the actual subjective experiences that these women have lived. These case studies illustrate the dual nature of, on the one hand, being female in a culture that prizes "fitting in" above all else, and on the other hand, a culture which acknowledges the sanctity of each individual life. Through the discussion of four women's sexual life stories we have endeavored to show how this duality exists within the minds and hearts simultaneously of these women. At the same time, we hope that further explorations of this dichotomy will shed light on the subject-object dilemma of female existence as it relates to their sexuality/sexual being, and how the issue of power vs powerlessness is experienced when cultural norms promote female objectivity, and the devastating effects that it has on the women who are the objectified population.

\section{ACKNOWLEDGEMENTS}

The authors would like to acknowledge the contribution made by the Collaborative Research Network (CRN) for Mental Health and Well-being in Rural Communities, supported by the Department of Industry, Innovation, Science, Research and Tertiary Education, Commonwealth Government of Australia.

\section{References}

1. Foucault, M. 1980. The History of Sexuality (R. Hurley, Trans.). New York: Vintage Books.

2. Deutsch, A.R., Hoffman, L. and Wilcox, B. L. 2013. "Sexual Self-Concept: Testing a Hypothetical Model for Men and Women." Journal of Sex Research. 0(0): 1-14. doi: 10.1080/00224499.2013.805315.

3. World Health Organization. (2002). Gender and human rights. Retrieved from http://www.who.int/reproductivehealth/topics/gender_rights/sexual_health/en/

4. Edwards, W.M. and Colemn, E. 2004. "Defining sexual health: A descriptive overview.”

5. Archives of Sexual Behavior, 33:189-195. doi: 10.1023/B:ASEB.0000026619.95734.d5

6. Polkinghorne, D. E. 2005. Language and Meaning: Data Collection in Qualitative Research. Journal of Counseling Psychology, 52(2): 137-145.

7. Daniluk, J. C. 1993. “The meaning of experience of female sexuality.” Psychology of Women Quarterly, 17: 53-69.

8. Ellison, C. R. 2000. Women's sexualities: Generations of women share intimate secrets of sexual selfacceptance. Oakland, CA: New Harbinger Publications. P.13.

9. Johnson, R. J., Rew, L., Fredland, N., \& Bowman, K. 2010. "Sexual self-concept In sxually abused homeless adolescents." Vulnerable Children and Youth Studies, 5(1): 44-51.pp.45.

10. McCabee, M.P., Aleporos, G., \& Dip, G. 2003. "Sexual esteem, sexual satisfaction and sexual behaviour among people with physical disability." Archives of Sexual behaviour, 32 (94): 359-369.

11. Crawford, M. and Popp, D. 2003. "Sexual double standards: A review and methodological critique of two decades of research." Journal of Sex Research, 40: 13-26.

12. doi:10.1080/00224490309552163

13. Pai, H. C., Lee, S., \& Yen, W.J. 2011. "The effect of sexual self-concept on sexual health behavioural intentions: a test of moderating mechanisms in early adolescent girls." Journal of Advanced Nursing, 1: 47-55.

14. Mahdavi, P. 2009. Iran's sexual revolution: Passionate uprising. Stanford, CA: Stanford University Press. 
15. Rezai-Rashti, G. M. 2007. "Transcending the limitations: Women and the post-revolutionary Iranian cinema." Critique: Critical Middle Eastern Studies, 16(2): 191-206.

16. Mobasher, M. 2006. "Cultural trauma and ethnic identity formation among Iranian immigrants in the United States." Journal of American Behavioural Scientist, 50(1): 100-117.

17. Shirpak, K. R., Maticka-Tyndale, E., \& Chinichian, M. 2007. "Iranian immigrants' perceptions of sexuality in Canada: A symbolic interactionist approach“ Canadian Journal of Human Sexuality, 16(3-4): 113-128.

18. Afary, J. 2009. Sexual Politics in Modern Iran, New York, NY: Cambridge University Press.

19. Maasoumi, M., Lamyian, F., Khalajabadi-F., Montazeri, A. 2013. “Women’s perception of sexual socialization in Iran: a qualitative study." Journal of Qualitative Research in Health Sciences, 2(3):221233.

20. Merghati-Khoeiab, E., Solhic, M., Nedjatd, S., Taghdisic, M. H., Shojaei Zadeh, D., Taketf, A. R., \& Zareic, M.K. 2014. "How a Divorcee's Sexual Life Is Socially Constructed and Understood in the Iranian Culture." Journal of Divorce \& Remarriage, 55(5): 335-347. doi:10./10502556.2014.921958

21. Janghorban, R., Roudsari, R. L., Taghipour, M. A. \& Loties, L. 2015. “The Shadow of Silence on the Sexual Rights of Married Iranian Women.” BioMed Research International.

22. Article ID 520827, 11 pages. http://dx.doi.org/10.1155/2015/

23. Iranian Americans Immigration and Assimilation. 2014 - Public Affairs Alliance

24. of Iranian Americans. http://www.paaia.org/CMS/Data/Sites/1/pdfs/iranian-americans---immigrationand-assimilation.pdf

25. Martin, K. A. 1996. Puberty, sexuality, and the self: Girls and boys at adolescence. New York: Routledge.

26. Tolman, D. 2002. Dilemmas of desire: Teenage girls talk about sexuality. Cambridge, MA:

27. Harvard University Press.

28. Aubrey, J. S. 2007. “Does television exposure influence college - aged women's sexual self-concept?” Journal of Media Psychology, 10: 157-181.doi: 10.1080/15213260701375561

29. Mollen, D., \& Stabb, S. D. 2010. “Women's sexuality and meaning making.” Journal of

30. Constructivist Psychology, 23(4): 295-320.doi: 10.1080/10720537.2010.502400

31. Marsh, H. W., \& Shavelson, R. 1985. "Self-concept: Its multifaceted, hierarchical

32. structure." Educational Psychologist, 20: 107 - 123. doi:10.1207/s1532698ep2003_1

33. O'Sullivan, L. F., Meyer-Bahlburg, H., F.L., \& McKeague, I. W. 2006. "The development of the sexual selfconcept inventory for early adolescent girls." Psychology of Women Quarterly, 30: 139-149. doi: 10.1111/j.1471-6402.2006.00277.x

34. Rostosky, S. S., Dekhtyar, O., Cupp, P. K., \& Anderman, E. M. 2008. "Sexual self-concept and sexual selfefficacy in adolescents: A possible clue to promoting sexual health?" Journal Of Sex Research, 45: 277 286. doi: 10.1080/00223390802204480

35. Winter, L. 1988. "The role of sexual self-concept in the use of contraceptives." Family Planning Perspectives, 20(3): 123-127.

36. Vickberg, S. M. J., and Deaux, K. 2005. "Measuring the dimensions of women's sexuality: The women's sexual self-concept scale." Sex Roles, 53(5/6): 361- 369. doi: 10.1007/s11199-005-6759-y

37. Curtin, N., Ward, L. M., Merriwether, A., \& Caruthers, A. 2011. "Femininity ideology and sexual health in young women: A focus on sexual knowledge, embodiment, and agency." International Journal of Sexual Health, 23:48-62.

38. Horne, S., and Zimmer-Gembeck, M. J. 2006. "The Female Sexual Subjectivity

39. Inventory: Development and validation of an instrument for late adolescents and emerging adults." Psychology of Women Quarterly, 30: 125-138. http://dx.doi.org/10.1111/j.1471-6402.2006.00276.x.

40. Oattes, M. K., and Offman, A. 2007. "Global self-esteem and sexual self-esteem as predictors of sexual communication in intimate relationships." The Canadian Journal of Human Sexuality, 16(3-4): 89-99. 
41. Peterson, Z. D. 2010. "What is sexual empowerment? A multidimensional and process oriented approach to adolescent girls' sexual empowerment." Sex Roles, 62: 307-313.

42. Snell, W. E. 1998. The Multidimensional Sexual Self-Concept Questionnaire. In C .M.

43. Davise, W. L. Yarber, R. Bauserman, G. Schreer \& S. L. Davis (Eds.), Handbook of sexuality-

44. related measures (pp.521 - 524). Thousand Oaks, CA: Sage.

45. Baumeister, R. F. and Twenge, J.M. 2002. "Cultural suppression of female sexuality."

46. Review of General Psychology, 6: 166 - 203.

47. Rickert, V. I., Sanghvi, R., \& Wiemann, C. M. 2002. "Is lack of sexual assertiveness among adolescent and young adult women a cause for concern?" Perspectives on Sexual and Reproductive Health, 34(4), 178183.

48. Schnarch, D. 2009. Intimacy and Desire: Awaken the passion in your relationship. New York, NY: Beaufort Books.

49. Baumeister, R. F. 2000. "Gender differences in erotic plasticity: The female sex drive as socially flexible and responsive." Psychological Bulletin, 126 (3): 347-374. doi: 10.1177/0044118X97029001001

50. Peplau, L. A., \& Garnets, L. D. 2000. “A new paradigm for understanding women's sexuality and sexual orientation." Journal of Social Issues, 56(2): 329-350. Doi:10.1111/00224537.00169

51. Foley, S., Kope, S. A., \& Sugrue, D. P. 2002. Sex matters for women. New York, NY: The Guilford Press. P.29.

52. Rashidian, M., Hussain, R., \& Minichiello, V. 2013. “'My culture haunts me no matter where go': IranianAmerican women discussing sexual and acculturation experiences." Culture, Health \& Sexuality: An International Journal for Research, Intervention and Care, 15(7): 866-877. Doi: 10.1080/13691058.2013.789128.

53. Minichiello, V., Madison, J., Hays, T., \& Parmenter, G. 2004. Doing qualitative in-depth interviews. In V. Minichiello, G. Sullivan, K. Greenwood, \& Axford, R. (Eds.), Handbook of Research Methods for Nursing and Health Science (2nd ed.) (pp. 410-446). Sydney, Austrailia: Pearson Education Australia.

54. Kinias, Z., and Kim, H.S. 2012. "Culture and gender inequality: Psychological consequences of perceiving gender inequality.” Group Processes \& Intergroup Relations. 15(1): 89-103. doi: $10.1177 / 1368430211408940$

55. Jones, T.W. 2013. "Religion, gender and sexuality in everyday life." Culture, Health \& Sexuality: An International Journal for Research, Intervention and Care. 15 (2):S180-S333. doi:10.1080/13691058.2013.831526

56. Stevens, D., Riger, G., \& Riley, P. J. 2001. Working hard and hardly working: Domestic labor and marital satisfaction among dual-earner couples. Journal of Marriage and Family, 63(2): 514-526.

57. Vahdaninia, M., Montazeri, A., \& Goshtasebi, A. 2009. "Help-seeking behaviors for female sexual dysfunctions: a cross sectional study from Iran." BMC Women's Health. 9:3. doi: 10.1186/1472-6874-9-3; http://www.biomedcentral.com/1472-6874/9/3. 